\title{
A sustainable approach to laboratory experimentation
}

\author{
Carlos Felgueiras, Ricardo Costa \\ Gustavo R. Alves, Clara Viegas, André Fidalgo, Maria Arcelina Marques, Natércia Lima \\ Polytechnic of Porto - School of Engineering, Portugal \\ $\{\mathrm{mcf}$, rjc, gca, mcm, anf, mmr, nmm\}@isep.ipp.pt \\ Manuel Castro \\ Universidad Nacional de Educación a Distancia, Universidad de Deusto, Spain zubia@deusto.es \\ Spain mcastro@ieec.uned.es \\ Andreas Pester \\ Carinthia University of Applied \\ Sciences, Austria \\ andreas.pester@gmail.com

Ana Pavani
Pontifícia Universidade Católica
do Rio de Janeiro, Brazil
apavani@puc-rio.br \\ Ruben Fernandez \\ Universidad Nacional de \\ Santiago del Estero, Argentina \\ raf@unse.edu.ar \\ Wlodek Kulesza \\ Blekinge Institute of \\ Technology, Sweden \\ wlodek.kulesza@bth.se \\ María Isabel Pozzo \\ IRICE-CONICET, Argentina \\ pozzo@irice-conicet.gov.ar \\ Vanderli Oliveira \\ Universidade Federal de Juiz de \\ Fora, Brazil \\ vanderli@acessa.com \\ Javier García-Zubía \\ Juarez Bento Silva \\ Universidade Federal de Santa \\ Catarina, Araranguá, Brazil \\ juarezbs.silva@gmail.com \\ Susana Marchisio \\ Universidad Nacional de \\ Rosario, Argentina \\ smarch@fceia.unr.edu.ar \\ Luis C. M. Schlichting \\ Instituto Federal de Santa \\ Catarina, Brazil \\ schlicht@ifsc.edu.br
}

\begin{abstract}
Sustainability is currently a general concern in society and in particular in the use of laboratories for educational purposes. Although laboratories are unavoidable facilities for education, they often produce waste resulting from students' experiments. To contribute for sustainable solutions in education, the use of remote laboratories instead of the traditional hands-on laboratories should be considered in every engineering course. It is precisely this aspect that is discussed in the current paper. Some comments about the importance of sustainability in education are made. Later, it is described the use of a remote laboratory named VISIR in a course held at the Polytechnic of Porto - School of Engineering, for the conduction of an electronic experiment named Schmitt Trigger. At the end, some comments about the contribution of this remote lab for sustainability in education, are provided.

Permission to make digital or hard copies of all or part of this work for personal or classroom use is granted without fee provided that copies are not made or distributed for profit or commercial advantage and that copies bear this notice and the full citation on the first page. Copyrights for components of this work owned by others than ACM must be honored. Abstracting with credit is permitted. To copy otherwise, or republish, to post on servers or to redistribute to lists, requires prior specific permission and/or a fee. Request permissions from Permissions@acm.org.

TEEM'19, October 16-18, 2019, León, Spain

(C) 2019 Association for Computing Machinery.

ACM ISBN 978-1-4503-7191-9/19/10...\$15.00

https://doi.org/10.1145/3362789.3362952
\end{abstract}

\section{CCS CONCEPTS}

- Applied Computing $\rightarrow$ Physical Sciences and Engineering;

- Applied Computing $\rightarrow$ Education;

\section{KEYWORDS}

Sustainability in higher education, Schmitt Trigger circuits, VISIR, remote labs, engineering education.

\begin{abstract}
ACM Reference format:
Carlos Felgueiras, Ricardo Costa, Gustavo R. Alves, Clara Viegas, André Fidalgo, Maria Arcelina Marques, Natércia Lima, Manuel Castro, Javier García-Zubía, Andreas Pester, Wlodek Kulesza, Juarez Bento Silva, Ana Pavani, María Isabel Pozzo, Susana Marchisio, Ruben Fernandez, Vanderli Oliveira and Luis C. M. Schlichting. 2019. A sustainable approach to laboratory experimentation. In Proceedings of the Seventh International Conference on Technological Ecosystems for Enhancing Multiculturality (TEEM 2019) (León, Spain, October 16-18, 2019), ACM, New York, NY, USA, 7 pages. https://doi.org/10.1145/3362789.3362952
\end{abstract}

\section{1 - Introduction}

Engineering is a practicing profession dedicated to harnessing or modifying some resources used for the creation of all technology [1]. This evidence is only possible by the inclusion of experimental training, through laboratory classes, in engineering education. Additionally, the skills demand for students are growing, which 
requires the inclusion of several learning objectives associated with the laboratory work [1-3]. Some of these learning objectives, listed in [1], imply a direct manipulation of objects under experimentation and the test of the equipment available in the traditional hands-on laboratories. Other learning objectives, however, may be addressed through nontraditional labs, such as virtual labs and remote labs. Each type of laboratory has its relative advantages in achieving the stated objectives, has already been discussed and presented in [1, 3 - 6]. Despite the educational requirements that force the use of real laboratories in higher education, with many publications emphasizing their importance and benefits for the teaching and learning process, it is important to create sustainable solutions, which means solutions that may contribute for a reduction of waste that will contribute to improve economy and environment.

The concept behind this main concern is often known as sustainability. A sustainable development is a widely cited concept due mainly to recent climate changes. The most quoted definition of sustainability refers: "...development that meets the needs of the present without compromising the ability of future generations to meet their own needs" [7]. A more direct technical interpretation for Engineering may be as follows: "A sustainable system is one that consumes the resources strictly necessary to obtain the desired effect" [8]. Focusing on this last definition, in hands-on labs there is a set of experiments that often result in waste that should be minimized. In the particular case of laboratories dedicated to electronic experiments, component disruption is often the result of various factors, the most common being the misuse. Traditional hands-on laboratories are scarce and costly resources that must be optimized $[9,10]$. From this point of view, Remote Laboratories lends itself especially to both objectives, as it reduces operating costs of replacing damaged components, and reduces the environmental impact, which means that less electronic waste is produced. The global impact resulting from this reduction is very important considering the huge number of educational laboratories to teach and learn electronics.

In this context, despite some published results [11, 27], an analysis on sustainability resulting from the use of Remote Laboratories is still incipient, which justifies that this type of studies should continue. A contribution to this type of study is made in this paper that focus on analyzing the importance of sustainability in education. Included as an infrastructure of the PILAR project [24], which basically aims to share different experiments through an international educational community, this paper describes the use of a remote laboratory named VISIR in a course held at the Polytechnic of Porto - School of Engineering. An electronic experiment named Schmitt Trigger is provided remotely using the VISIR and, at the end, some comments about the contribution of this remote lab for sustainability in education are provided.

This the paper is organized as follows: section 2 provides some comments about the fundamental objectives on engineering, complemented with the characteristics that a traditional hands-on lab has compared to a remote laboratory like VISIR. Section 3 presents a case study on the adoption of the remote lab VISIR in an electronic course, and some comments regarding the sustainable approach this solution brings to the course. The papers ends with a conclusion.

\section{2 - Lab experiments with electronic circuits}

\section{1 - The Fundamental Objectives on Engineering}

In engineering education, laboratory classes are fundamental in order to give to students the required technical skills. These are obtained by completing a set of 13 learning objectives that are associated with instructional laboratories in Engineering undergraduate curricula [1-3]. Three of them is analyzed in the scope of this paper, namely:

Objective 3: Experiment. "Devise an experimental approach, specify appropriate equipment and procedures, implement these procedures, and interpret the resulting data to characterize an engineering material, component, or system."

Objective 6: Learn from Failure. "Identify unsuccessful outcomes due to faulty equipment, parts, code, construction, process, or design, and then re-engineer effective solutions".

Objective 7: Creativity. "Demonstrate appropriate levels of independent thought, creativity, and capability in real-world problem solving".

These three objectives show that it is important that students have a high degree of autonomy, which can only be obtained by making mistakes. Although equipment is traditionally protected against misuse, components can be often destroyed, by exceeding the maximum limits stated by the manufacturers, which can lead to a waste of components, and therefore a decrease on the sustainability essence. This means that the conduction of a laboratorial experiment should in part be controlled, and a choice between traditional hands-on labs or remote labs should be analyzed.

\section{2 - Traditional laboratories (hands-on labs)}

An experiment with electrical or electronic components is associated with a reasonably fixed procedure. First, the electronic components are placed on a breadboard. Later, the circuit is supplied with a Direct Current (DC) power supply stimulated with a Function Generator. Finally, measurements are taken with a Digital Multimeter (DMM) and / or an Oscilloscope. These different measurement instruments and the breadboard are generically provided in a similar way in the electronic benches of every school / college. Nevertheless, the way students implement the circuit on breadboard is usually very distinct.

Early-stage students, and therefore with little experience, tend to confuse components. When they find that the component, they are looking for is not the right one they quickly set it aside and pick up another. At the end of the class there is often a jumble of mixed components making their reuse almost impossible. To avoid this situation and increase the sustainability by reducing the waste of components, before the laboratory class the teacher separates the components into small plastic bags for each workgroup experiment, as illustrated in figure 1. This way, the components can be reused in the next class. Setup the circuits on the breadboard without welding is different from student to student. Early stage students (with less practice) tend to over-stress component pins. As a result, component pins tend to break under stress, typically near the body of the component. The number of uses that each 
component endures depends on the stress it has been subjected to, and the type of material that constitutes the pin.

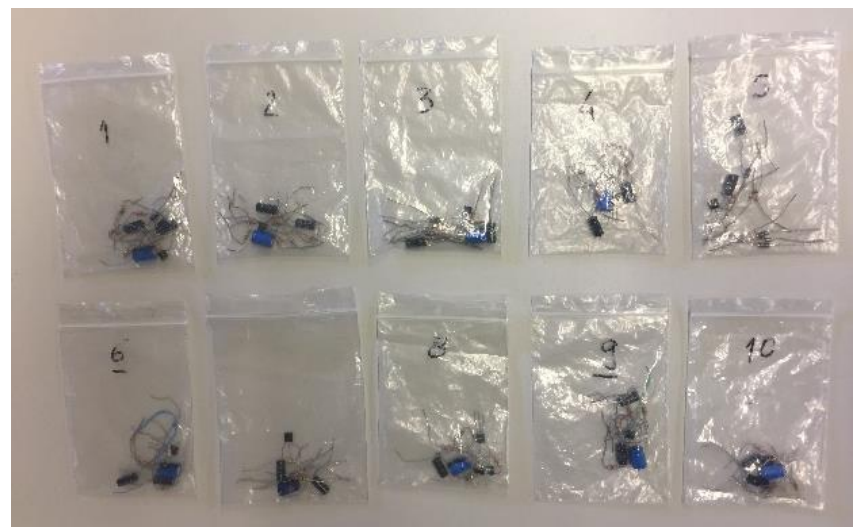

Figure 1: Typical set of components for a laboratory class.

For example, resistors can withstand more than 30 stress actions, while a transistor pin can withstand no more than 2 or 3 actions. Figure 2 shows a set of components used for setting up a full wave rectifier experiment, where one resistor is broken due to stress.

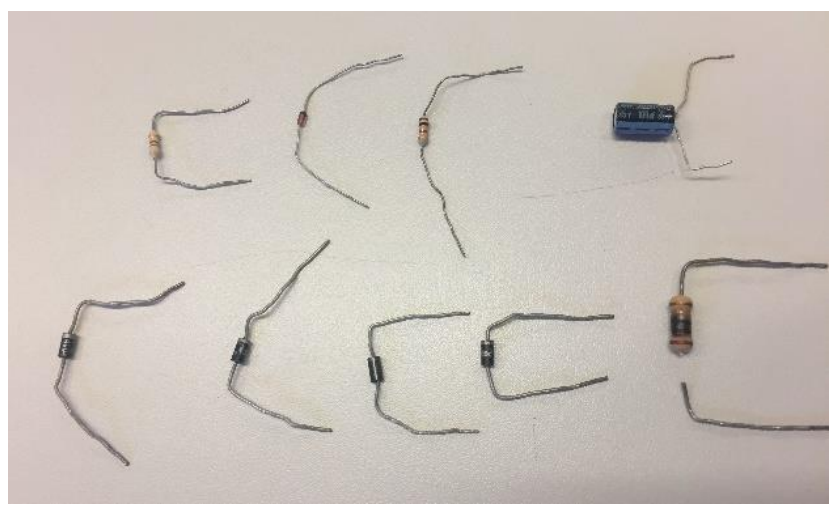

Figure 2: A set of components used in a full-wave rectifier experiment.

Figure 3 shows a set of transistors used in a Common Emitter configuration amplifier experience. Note that the transistor pins are too stressed. Also note the detail of some having the Base pin bent, an action taken by students to allow the current to be measured experimentally on that pin. This justifies the broken base pin in one of the components.

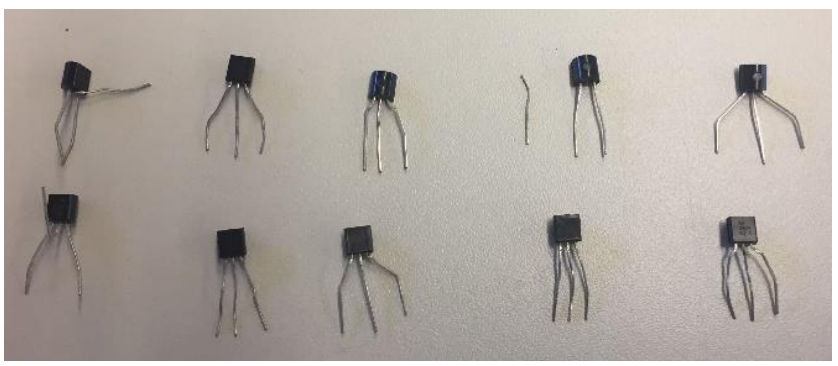

Figure 3: A set of components used in a Common Emitter configuration amplifier experience.
Figure 4 shows some operational amplifiers (AmpOp) after their use for 12 times. Note the condition of the pins. One is broken due to not having supported position correction action.

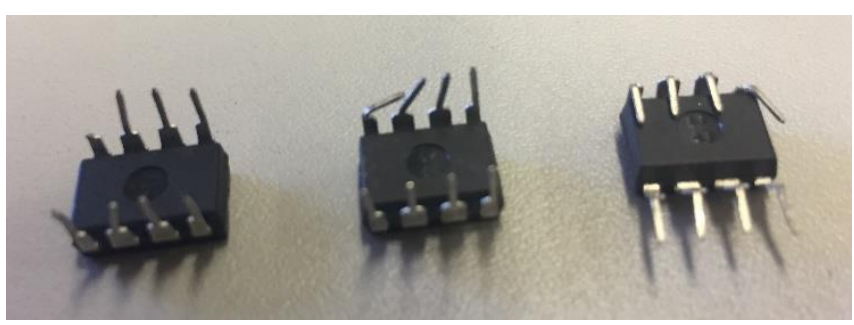

Figure 4: A set of Operational Amplifiers after being used by students.

In sum, in traditional hands-on labs, broken electronic components is an important part of produced waste. Possible measures seek to reduce waste, but mechanical stress margins limit the reuse of a component to only about 20 times. To overcome this aspect that contributes to a decrease on the sustainability essence, a remote lab as the VISIR could be considered to provide a remote access to a real laboratory.

\section{3 - The VISIR Remote Lab}

Virtual Instrument Systems in Reality (VISIR) is a Remote Laboratory for electrical and electronic experiments. It is currently the best and most known remote laboratory, with over 100 technical and scientific publications (e.g. [12 - 22]). It was initially developed in Karlskrona - Sweden and is currently installed in Bilbao and Madrid (Spain), Porto (Portugal), Villach and Vienna (Austria); Madras (India), Batumi (Georgia), Settat (Morocco), Rosario and Santiago del Estero (Argentina), Araranguá, Florianópolis and Rio de Janeiro (Brazil) and San José (Costa Rica). VISIR includes a set of measurement instruments able to be interconnected to form a traditional electronic circuit. The circuit is remotely setup by the students using a virtual breadboard. Additionally, a set of measurement instruments (a triple DC power supply, a Function Generator, a DMM, an Oscilloscope) can be attached to any node of the circuit thanks to a switch matrix provided in the VISIR infrastructure, all controlled by a PXI instrumentation bus. Figure 5 illustrates a block diagram of the VISIR infrastructure, and figure 6 the VISIR interface used by students to setup the electronic circuits.

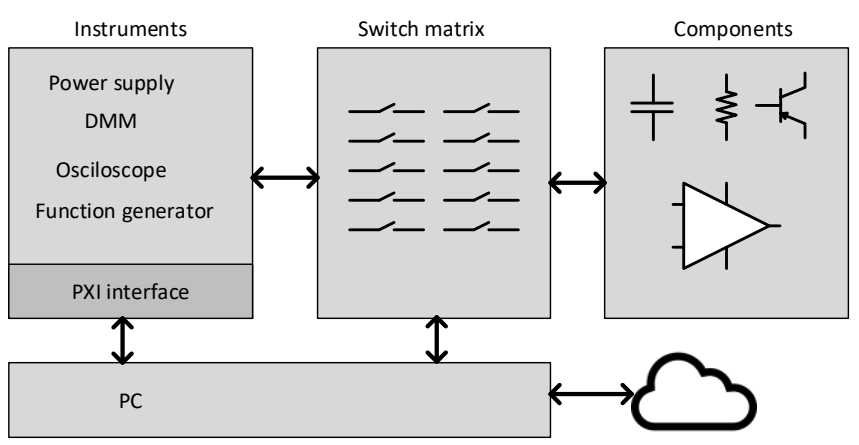

Figure 5: The VISIR block diagram. 


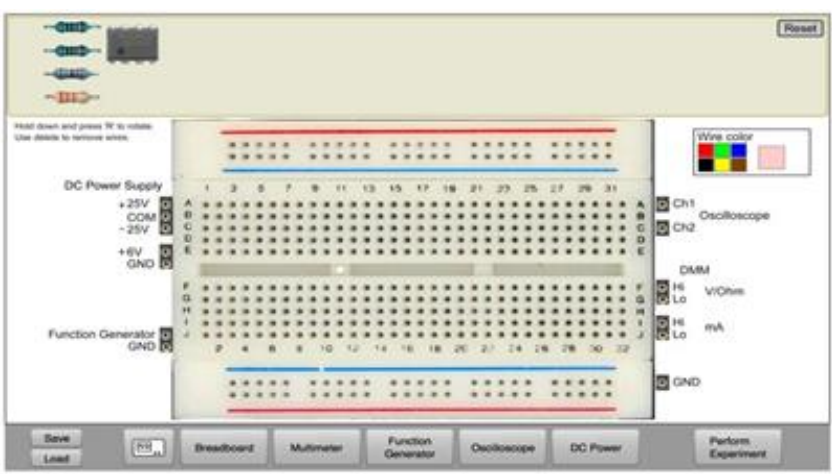

Figure 6: The VISIR interface used by students to setup electronic circuits.

With the VISIR students perform experiments in the same way as they do in a traditional hands-on laboratory:

1- The student places the components on the breadboard and connect them to the power supply and / or to other equipment, and presses the "Run Experiment" button;

2- Remotely the VISIR configures the switch matrix to execute the entire circuit structure, configures the equipment, makes the measurements and sends the results back to the student.

Since the entire process is made remotely, students do not have the opportunity of damaging the components as they traditionally do in a hands-on lab. Therefore, components have a very long lifetime duration. The only mechanical stress is the one associated to the relays used in the switch matrix that have a limit of action greater than one million. The electrical limits of the components are not exceeded as the system only allows operation within the limits set by the experiment designer.

Therefore, taking into consideration a sustainable approach focusing on avoiding the waste of component, a typical Schmitt Trigger electronic experiment was prepared in the VISIR for course named Applied Electronics held at the Polytechnic of Porto School of Engineering.

\section{3 - Case study}

Sustainability comprises different areas always seeking for improving people life. A sustainable experiment in engineering should seek to reduce costs in their setup and use, should reduce the waste of components and should contribute to avoid time and geographic constrains for users' access. Considering this, the use of a remote experiment of a Schmitt Trigger circuit developed using an AmOp in a course named Applied Electronics (ELEAPL) conducted at the Polytechnic of Porto at the School of Engineering (IPP/ISEP) was prepared. Its adoption in this course was fundamental to guarantee a sustainable approach, since the course has more than 200 students, which means that setting up 200 experiments would be costly and will lead to a huge waste of components. Moreover, the physical conditions to give the lab facilities and the components to setup the experiment to all these students would be impracticable. If students have access to a real lab whenever they want using a simple connection to the internet, they will have time for other activates, improving therefore their life quality, given them also an academic resource that will facilitate their learning as already proved by many studies [23][26].

The program of the ELEAPL course included the topic of Schmitt Triggers. One of the outcomes of this course was to learn how to idealize and setup a Schmitt Trigger circuit using an AmpOp integrated circuit. Students should learn the importance of including hysteresis in a comparator, and they should learn how to define the hysterics interval. Supported by previous theoretical issues taught in the classes of ELEAPL, students acquired the required knowledge to mathematically analyze a Schmitt Trigger circuit in order to determine the values required to setup the associated electronic components. Supported on their values, they were also able to simulate the obtained circuit using the PS-SPICE software giving them the possibility to verify their calculations.

However, in engineering, it is fundamental to verify the obtained results, and the best way to do that is to experiment a real circuit. This means that issues thought in a well-designed course should comprises an experimental activity using real instruments and devices, which means students should have access to a real laboratory. A simulation could be an intermediate step, but only a real experiment can give the certainties that all calculations were correctly made. In other words, a real contact with nature is always the best way to learn engineering [25]. Therefore, and seeking for a sustainable approach, and in particular the waste of components traditionally associated to hands-on labs, a simple circuit was arranged in the VISIR system, namely a Schmitt Trigger implemented as an inverter comparator.

\section{1 - The Schmitt Trigger experiment}

In electronics, a Schmitt Trigger is a comparator circuit with hysteresis that can be implemented by applying a positive feedback to the non-inverting input of an operational amplifier. It converts an analog input signal to a digital output signal that retains its value until the input changes. The use of a positive feedback avoids that noises that may exist in the input signal can take to unstable outputs. Figure 7 represents a Schmitt Trigger and its output signal implemented as non-inverter comparator with hysteresis using an OpAmp, since the input signal (Vi) is applied to the non-inverter input and it is compared with a threshold Commutation Point (VCP) that is a DC voltage created by a voltage divider formed by $\mathrm{R} 2$ and R3.

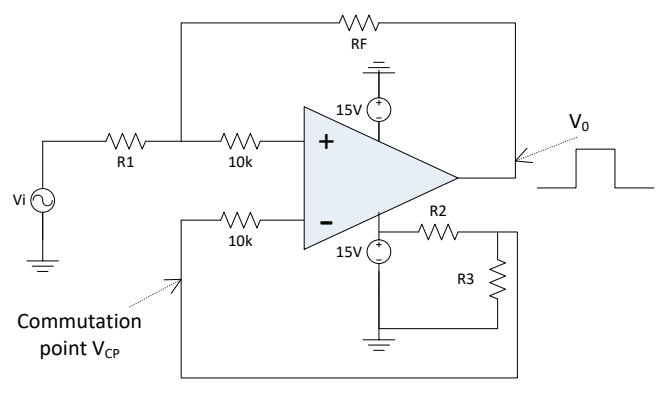

Figure 7: Schmitt Trigger implemented as a non- inverter comparator with an AmpOp.

As represented in the graphs of figure 8, the positive feedback allows that the VCP has two distinct voltages: an high threshold Voltage Commutation Point (VCPH) and a lower threshold Voltage 
Commutation Point (VCPL). The input signal Vi is compared with the VCPH and VCPL to change the Vo. When the Vi is higher than the VCPH, Vo goes up (the AmpOp is saturated to $\approx+15 \mathrm{~V}$ ), when $\mathrm{Vi}$ goes lower than VCPL, Vo goes down (the AmpOp is saturated to $\approx-15 \mathrm{~V}$ ). The difference between VCPH and VCPL is called Hysteresis Voltage and represents the maximum noise allowed in the Vi signal before a commutation in Vo. Both voltages VCPH and the VCPL are calculated according to the previous level of Vo using the following formula, that can be obtained by analyzing the circuit.

$$
v_{i}=v_{C P}\left(\frac{R_{F}+R_{1}}{R_{F}}\right)-\frac{R_{1}}{R_{F}} v_{o}
$$

Therefore

If $\mathrm{v} 0=-15 \mathrm{~V}$, it means:

$$
v_{i}>v_{C P}\left(\frac{R_{F}+R_{1}}{R_{F}}\right)-\frac{R_{1}}{R_{F}}(-15) \rightarrow v_{C P H}=v_{i}
$$

If $\mathrm{v} 0=+15 \mathrm{~V}$, which means:

$$
v_{i}<v_{C P}\left(\frac{R_{F}+R_{1}}{R_{F}}\right)-\frac{R_{1}}{R_{F}}(+15) \rightarrow v_{C P L}=v_{i}
$$

Since the ELEAP course has many students, setting up this experiment for all of them would be impracticable, since costs will drastically increase in terms of components and measurement instruments and the physical facilities would be difficult to provide. Therefore, this same experiment was provided in the VISIR system, giving the required facility for students' access, and reducing the costs that the institution will have if many experiments were setup, in particular in the waste of components. To enable students' interaction with the experiment a guide was previously prepared. Through this guide, students had the possibility to verify in reality the previous calculations and simulations made to the presented Schmitt Trigger circuit, in a sustainable way, since it contributes to:

1- lower costs, since a single experiment, and associated measurement instrumentations are sharable by all students, which means a drastically reductions of costs when compared to the eventual necessity of setting up one experiment for each student (or group of students);

2- reduce the waste of components, since the circuit was already predefined in the VISIR system, which means that the step of setting up an experiment in a hands-on approach was not considered;

3- increase the versatility in the conduction of a real experiment, since students have access to a real laboratory without time and geographical constrains, giving them more time for other activities.

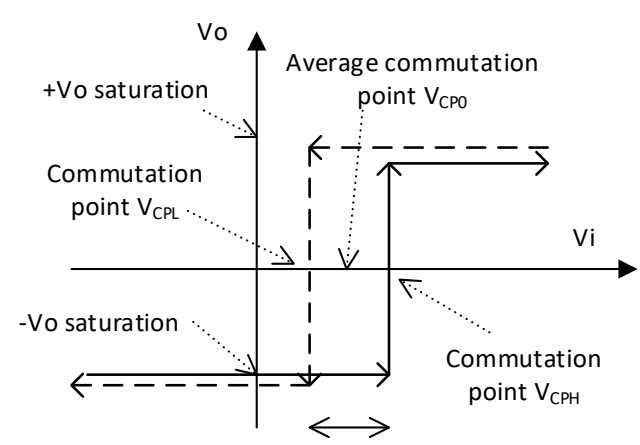

Hysteresis

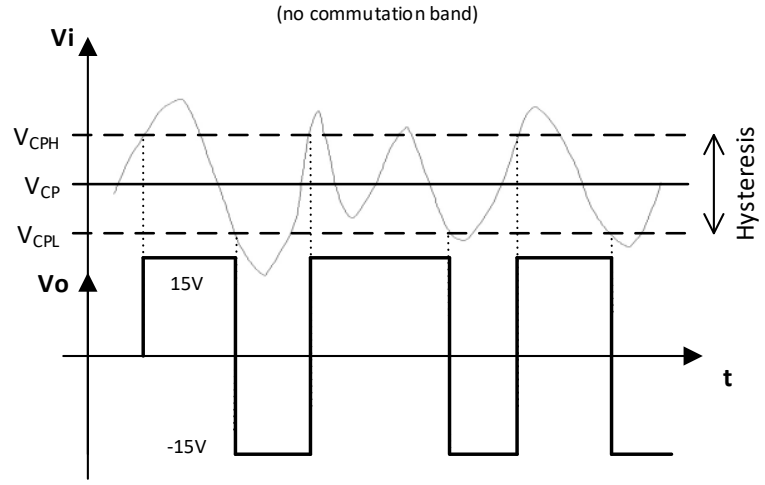

Figure 8: Transfer function and the time behavior of the Schmitt Trigger circuit implemented as a non-inverter comparator with hysteresis.

\section{2 - The guide provided to students}

During the classes of ELEAPL several calculations were presented to students and they were able to observe simulations using the PSSPICE software in order to prove the obtained values found for setting up a Schmitt Trigger circuit. However, teaching and learning electronics require practical activities, in particular a contact with real equipment. A simulation is supported by software modules, which means that even if those modules have a good quality, there are no comparison with reality, which can only be obtained by using a real laboratory. The solution of a hands-on laboratory could had been suggested; however, sustainable issues were taken into consideration for using the remote laboratory VISIR, as already indicated.

An introduction to the VISIR system and to the experiment to all classes were made, and a guide tutorial was prepared so students can idealize and setup the circuit. The tutorial was divided in three parts: an introduction to Schmitt Trigger, which is in fact very similar to the one described in the previous section, and a set of questions that obliged students to make calculations, simulate the circuit using the PS-SPICE simulator, and conduct a real experimentation using the VISIR. The tutorial mainly focuses on providing the ability for students to verify the behavior of a Schmitt Trigger circuit. They already had the schematic of the circuit and the adopted components. The goal is to see the hysteresis and validate previous calculations. The questions posed in the guide were the following:

1. Calculate VCPH and VCPL and indicate the maximum noise that may exist in Vi to avoid instability in Vo; 
2. Setup the circuit in the VISIR and, by applying a sinusoidal wave described according to the following formula vi=A. $\sin (2 . \pi \cdot 1000 \mathrm{t})+2,63 \mathrm{~V}$, where $\mathrm{A}$ is a variable amplitude, verify if the previous calculations are in accordance with the real behavior of the circuit, indicating the VCPL and the VCPH, and the associated maximum noise that may exist in Vi to avoid instability in Vo;

3. After experimentally determining the VCPL and the VCPH take some screenshots of the Oscilloscope in the exact instants of commutations, displaying the Vin, defined in the Function Generator (VMAX and VOffset), and the Vo.;

4. In those same conditions, using the Digital MultiMeter (DMM), observe the voltage in the non-inverter and inverter terminals and take a screenshot.

5. Supported by the answers to the previous questions, please comment your results, taking into consideration that we are dealing with real hardware and real components.

To answer all these questions, student had to setup the circuit in the VISIR, as illustrated in figure 9.

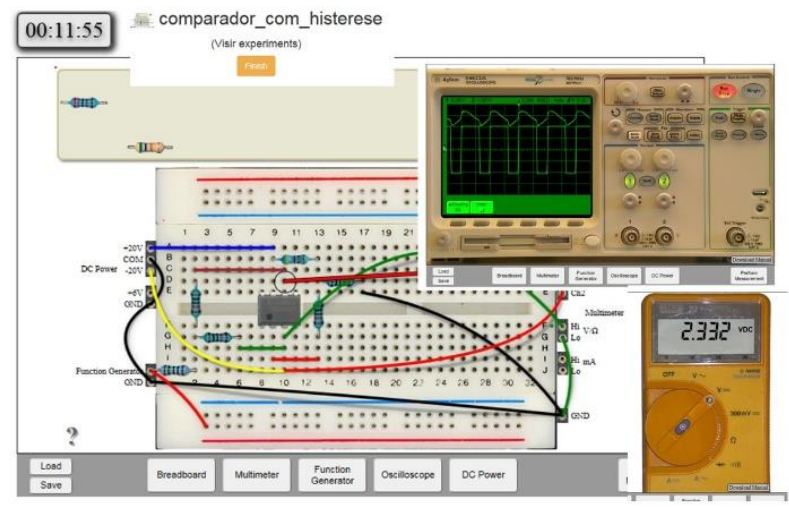

Figure 9: The Schimitt Trigger circuit setup in the VISIR.

Students were able to setup the circuit and use the traditional measurement instruments available in a hands-on lab. Since the VISIR uses an asynchronous access to the laboratory, which means that there are no necessity to define a schedule for each access (the VISIR manage all accesses in a transparent way), it can be classified as a sustainable system, since students gain versatility using a real laboratory with an effective reduction of costs.

\section{4 - Costs analysis}

To analyse the costs associated when comparing the use of VISIR and a traditional hands-on lab for the selected experiment, it is reasonable to make a distinction between two type of costs: i) direct and ii) indirect.

The indirect costs are related to issues like students travel costs to go to a laboratory, the requirement for lab facilities, the required energy to power-on an experiment, etc. These types of costs are difficult to quantify, but they may be very relevant when comparing both type of laboratories. In fact, a hands-on lab are not always power-on, but students have travel costs, and requires a place to setup each experiment (more room facilities). On the other side a remote laboratory, like VISIR, saves in the required facilities. A single room is enough to provide the remote lab infrastructure, travel costs are not considered since it provides an access through the internet to a real experiment in a $7 / 24$ basis, despite the experiment must be always power on since it is sharable among all students.

The direct costs can be more exactly analysed for this experiment. Its analysis can be evaluated in 2 issues: i) the waste of component costs and; ii) the required measurement instruments.
Table 1 lists the number and an estimated price of the components and the equipment required to conduct the experiment.

Table 1: Associated cost for setting up the Schmitt Trigger experiment.

\begin{tabular}{l|c|c|c}
\hline & Quantity & Unit price (€) & Total (€) \\
\hline Resistors & 6 & 0,10 & 0,60 \\
\hline AmpOp & 1 & 0,50 & 0,50 \\
\hline Bread Board & 1 & 7,0 & 7,0 \\
\hline Function Generator & 1 & 100,00 & 100,00 \\
\hline Oscilloscope & 1 & 240,00 & 240,00 \\
\hline Power source & 1 & 50,00 & 50,00 \\
\hline MultiMeter & 1 & 50,00 & 50,00 \\
\hline \multicolumn{3}{|c|}{ Total (without component waste) } & 448,10 \\
\hline
\end{tabular}

As indicated in the beginning of this paper, it is important to consider the waste of components that students traditionally have for setting up the circuit in a hands-on laboratory (many broken resistance pins; AmpOps are incorrectly connected, etc.). Based on our expertise as teachers, it is reasonable to consider about $20 \%$ of component waste per experiment. This means that excluding the measurement instruments required to conduct the experiment, each experiment have an estimated cost of $(6 \times 0,10+0,5) \times 1,20+7=$ $8,32 €$. If this component costs are added to the measurement instruments, a total price of about $448,32 €$ is reasonable to consider.

By adopting the VISIR to run the experiment, some costs can be supressed, in particular the one related to the waste of components and the use of instrumentation. However, a VISIR system may cost about $10000 €$. This means that providing a single remote experiment may have a cost of about $10001,10 €$, which in fact is too much when compared to a single experiment using a traditional hands-on lab. But, the waste of components will decrease, which means it can contribute to a sustainable choice concerning the environment issue (less waste less pollution).

According to the indicative costs, it is also easy to understand that the adopted remote laboratory is more cost sustainable when the number of students increase, since it is sharable, and there are no waste of components in the setup process. According to the costs indicated in the previous table and to the associated calculations, the use of the VISIR system for the particular Schmitt Trigger experiment is adequate when the number of students is more than 22, otherwise the use of a traditional hands-on lab should be considered.

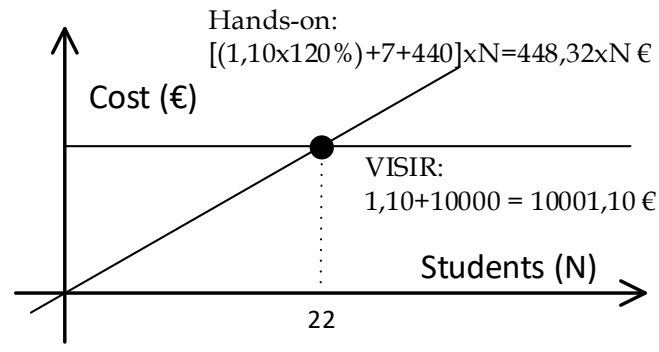

Figure 10: Indicative graph of costs associated to the Schmitt Trigger experiment: hands-on lab vs VISIR remote lab. 


\section{4 - Conclusion}

The experimental work is fundamental for every engineering course and in particular in electrical engineering courses. Despite simulations are often used to overcome institutions limitations due to the lack of laboratories and associated costs, the access to a real laboratory is fundamental. Two solutions can be considered: traditional hand-on laboratories or remote laboratories. Both give access to real equipment, but if we concentrate our analysis in sustainability issues, in particular in the associate waste of components that usually a hands-on lab has, remote laboratories can be an ideal solution. Therefore, this paper alerted readers to the common waste of components that exists in traditional hands-on labs and indicates as a possible solution the use of a remote lab. Through a remote lab, such as VISIR, students can setup circuits and access real equipment as they do in a traditional hands-on lab. Concerning sustainability issues, it was shown that using a remote lab decrease drastically the waste of components since students may setup the circuit without damaging the equipment and components. Wastes are drastically reduced, and in most situations without compromising the educational purposes. Moreover, and if all costs are considered the use of a remote lab would be also interesting when the number of students increase.

\section{ACKNOWLEDGMENTS}

The authors would like to acknowledge the support of the VISIR Community as well as the financial support provided by the Foundation for Science and Technology Project, FCT UID/EQU/00305/2013. The authors also acknowledge the support of the PILAR project (Platform Integration of Laboratories based on the Architecture of visiR), Erasmus+ Strategic Partnership $\mathrm{n}^{\circ}$ 2016-1-ES01-KA203-025327 and financial support of the project UID/EQU/00305/2013 - Center for Innovation in Engineering and Industrial Technology - CIETI.

\section{REFERENCES}

[1] L. Feisel and A. Rosa, "The role of the Laboratory in the Undergraduate Engineering Education”, Journal of Engineering Education, January, 2005.

[2] J. R. Brinson, "Learning outcome achievement in non-traditional (virtual and remote) versus traditional (hands-on) laboratories". Computers in Education 87(C):218-237. 2015. https://doi.org/10. 1016/j.compedu.2015.07.003

[3] Teresa Restivo and Gustavo R. Alves, Chapter 13. "Acquisition of higher order experimental skills through remote and virtual laboratories”. In IT Innovative Practices in Secondary Schools: Remote Experiments, Olga Dziabenko and Javier García-Zubía (Eds). Universidad de Deusto, Bilbao, 2013. pp. 321-347. ISBN 97884- 15759-16-4.

[4] J. Ma and J. Nickerson, "Hands-on, simulated, and remote laboratories: A comparative literature review," Computer Surveys, vol. 38, no. 3, 2006, Art. no. 7.

[5] L. Gomes and J. García-Zubía (Eds.). 2007. Advances on remote laboratories and elearning experiences”. Universidad de Deusto Press, Bilbao. ISBN 97884-9830-0772.

[6] Lyle Feisel and G. D. Peterson, "A Colloquy on Learning Objectives for Engineering Educational Laboratories," 2002 ASEE Annual Conference and Exposition, Montreal, Ontario, Canada, June 16-19, 2002.

[7] United Nations, World Commission on Environment and Development. (1987) Our Common Future, Oxford University Press, Oxford 27. ISBN 019282080X

[8] N. Caetano, J. Rocha, J.C. Quadrado, M.C. Felgueiras. (2017). Sustainable energies - the beauty and the beast. In Proceedings of SEFI 2017 - 45th Annual Conference: Education Excellence for Sustainability, Azores - Portugal.

[9] Jeffrey V.Nickerson; James E.Corter; Sven K.Esche; Constantin Chassapis; A model for evaluating the effectiveness of remote engineering laboratories and simulations in education; Computers \& Education; Volume 49, Issue 3, November 2007, Pages 708-725

[10] Cooper, M. and Ferreira, J. M. M. (2009). Remote laboratories extending access to science and engineering curricular. IEEE Transactions on Learning Technologies, 2(4) pp. 342-353.
[11] Gustavo R. Alves, Manuel Felgueiras, Clara Viegas, André Fidalgo, Maria Arcelina Marques, Ricardo Costa, Natércia Lima, Manuel Castro, Javier García-Zubía, Andreas Pester, Wlodek Kulesza, Juarez Bento Silva, Ana Pavani, María Isabel Pozzo, Susana Marchisio, Ruben Fernandez, Vanderli Oliveira, and Luis C. M. Schlichting. 2018. A sustainable approach to let students do more real experiments with electrical and electronic circuits. In Proceedings of the Sixth International Conference on Technological Ecosystems for Enhancing Multiculturality (TEEM'18), Francisco José García-Peñalvo (Ed.). ACM, New York, NY, USA, 508-514. DOI: https://doi.org/10.1145/3284179.3284265.

[12] Natércia Lima, Clara Viegas, Gustavo R. Alves, and Francisco J. GarcíaPeñalvo; "VISIR's Usage as a Learning Resource: a Review of the Empirical Research", Proceedings of the $4^{\text {th }}$ International Conference on Technological Ecosystems for Enhancing Multiculturality (TEEM'16), Salamanca, Spain, November 2-4, 2016. http://dx.doi.org/10.1145/3012430.3012623

[13] I. Gustavsson, G. Alves, C. R., K. Nilsson, J. Zackrisson, U. Hernandez-Jayo and J. García-Zubía, "The VISIR Open Lab Platform 5.0 - an architecture for a federation of remote laboratories," in REV 2011: 8th International Conference on Remote Engineering and Virtual Instrumentation, Brasov, Romania, 2011.

[14] A. V. Fidalgo, G. R. Alves, M. A. Marques, M. C. Viegas, M. C. Costa-Lobo, U. Hernadez-Jayo, J. García-Zubía and I. Gustavsson, "Adapting Remote Labs to Learning Scenarios: Case Studies Using VISIR and RemotElectLab," IEEE Revista Iberoamericana de Tecnologias del Aprendizage, VOL. 9, NO. 1, pp. 33-39, 2014.

[15] I. Gustavsson, J. Zackrisson, K. Nilsson, J. Garcia-Zubia, L. Hakansson, I. Claesson and T. Lago, "A Flexible Electronics Laboratory with Local and Remote Workbenches in a Grid," International Journal of Online Engineering (iJOE), Vols. Vol. 4, no 2, pp. 12-16, 2008.

[16] I. Gustavsson, L. Claesson, K. Nilsson, G.-Z. J. Zackrisson, U. HernandezJayo, L. Hakansson, J. S. Bartunek, T. Lago and I. Claesson, "The VISIR Open Lab Platform," in Internet Accessible Remote Laboratories: Scalable E- Learning Tools for Engineering and Science Disciplines, Abul K. M. Azad, Michael E. Auer, V. Judson Harward, 2012, pp. 294-317.

[17] C. M. Costa-Lobo, G. R. Alves, M. Marque, C. Viegas, R. G. Barral, R. J. Couto, F. L. Jacob, C. A. Ramos, G. M. Vilão, D. S. Covita, J. Alves, P. Guimarães, and I. Gustavsson, "Using Remote Experimentation in a Large Undergraduate Course: Initial Findings," in Proceedings of the 2011 Frontiers in Education Conference (FIE'11), 41st Edition, Rapid City, South Dakota, US, 2011.

[18] J. García-Zubía, U. Hernandez, I. Gustavsson and G. Alves, "Academic Effectiveness of VISIR remote lab in analog electronics," in $1^{\text {st }}$ Experiment@ International Conference, Lisbon, Portugal, 17-18 November, 2011.

[19] S. Odeh, G. R. Alves, M. Anabtawi, M. Jazi, M. Arekat and I. Gustavsson, "Experiences with Deploying VISIR at Al- Quds University in Jerusalem," in IEEE Global Engineering Education Conference (EDUCON), Harbiye, Istanbul, Turkey, 2014.

[20] M. Tawfik, E. Sancristobal, S. Martin, C. Gil, A. Pesquera, P. Losada, Diaz, G., J. Peire, M. Castro, J. García-Zubía, U. Hernández, P. Orduña, I. Angulo, M. C. C. Lobo, M. A. Marques, Viegas, M. C. and G. R. Alves, "VISIR: Experiences and challenges," International Journal Online Engineering (iJOE), vol. Vol 8, 2012.

[21] Gustavo R. Alves et al. "Spreading remote lab usage a system - A community A Federation," $2^{\text {nd }}$ International Conference of the Portuguese Society for Engineering Education (CISPEE) 2016.

[22] I. Gustavsson, K. Nilsson, J. Zackrisson, J. García-Zubía, h.- J. U., A. Nafalsky, Z. Nedic, O. Gol, J. Machotka, M. L. Pettersson, T. Lago and L. Hakansson, "On Objectives of Instructional Laboratories, Individual Assessment and Use of Collaborative Remote Laboratories," IEEE Transactions on Learning Technologies, Vols. Vol. 2, No 4, pp. 263-274, 2009.

[23] Ricardo Costa, et al., "A reconfigurable and expandable kit to teach electronic circuits based on Operational Amplifiers", Congreso TAEE (Tecnología, Aprendizaje y Enseñanza de la Electrónica), San Cristóbal de La Laguna, Tenerife, june 20-22, 2018

[24] Gustavo Alves, et al., "Spreading remote labs usage: A System - A Community A Federation", 2nd International Conference of the Portuguese Society for Engineering Education (CISPEE2016), Vila Real, Portugal, 20-21 October 2016.

[25] Javier García Zubía and Gustavo R. Alves (eds.), "Using Remote Labs in EducationTwo Little Ducks in Remote Experimentation”, ed. University of Deusto, 2011.

[26] Gustavo R. Alves, et al. International Cooperation for Remote Lab use. In: Higher Engineering Education. Maria M. Nascimento, Gustavo R. Alves, and Eva A Morais (Eds.). Springer, ISBN 978-981-10-8916-9, Chapter 1, pp. 7-38, 2017.

[27] Manuel Felgueiras and Nidia Caetano, "TEEM'18 - Track 7. Advances on Sustainable Development in Higher Education - Editorial”, Proceedings of the 6th Technological Ecosystems for Enhancing Multiculturality, Salamanca, Spain, 24-26 October 2018. Scopus. 